Mycobacterium microti infection in wild boar (Sus scrofa). Transbound Emerg Dis. 2016;63:e381-8. https://doi.org/10.1111/ tbed.12313

10. Brodin P, Eiglmeier K, Marmiesse M, Billault A, Garnier T, Niemann $\mathrm{S}$, et al. Bacterial artificial chromosome-based comparative genomic analysis identifies Mycobacterium microti as a natural ESAT-6 deletion mutant. Infect Immun. 2002;70:5568-78. https://doi.org/10.1128/IAI.70.10.5568-5578.2002

Address for correspondence: Bernat Pérez de Val, Institut de Recerca i Tecnologia Agroalimentàries-Centre de Recerca en Sanitat Animal, Edifici CReSA. Campus UAB (Bellaterra), Bellaterra, Barcelona 08193, Spain; email: bernat.perez@irta.cat

\section{Availability of Injectable Antimicrobial Drugs for Gonorrhea and Syphilis, United States, 2016}

\section{William S. Pearson, Donald K. Cherry, Jami S. Leichliter, Laura H. Bachmann, Nicole A. Cummings, Matthew Hogben}

Author affiliations: Centers for Disease Control and Prevention, Atlanta, Georgia, USA (W.S. Pearson, J.S. Leichliter, L.H. Bachmann, M. Hogben); Centers for Disease Control and Prevention, Hyattsville, Maryland, USA (D.K. Cherry, N.A. Cummings)

DOI: https://doi.org/10.3201/eid2511.190764

We estimated the availability of the injectable antimicrobial drugs recommended for point-of-care treatment of gonorrhea and syphilis among US physicians who evaluated patients with sexually transmitted infections in 2016. Most physicians did not have these drugs available on-site. Further research is needed to determine the reasons for the unavailability of these drugs.

$\mathrm{R}$ ates of sexually transmitted infections (STIs) are on the rise in the United States. Compared with the incidence in 2013, the numbers of reported gonorrhea $(+75 \%)$ and syphilis (primary and secondary, $+153 \%$ ) cases in 2017 were dramatically increased (1). Timely (optimally sameday) treatment of bacterial STIs with a highly effective regimen is critical for national STI control efforts and can help mitigate the development of drug resistance, a particularly pertinent issue for Neisseria gonorrhoeae (2). In addition, the high number of congenital syphilis cases in the United States in 2017 highlights the need for efficient and effective treatment of Treponema pallidum infection (3).

The recommended first-line treatment for uncomplicated gonorrhea is intramuscular ceftriaxone $(250 \mathrm{mg})$ and for primary and secondary syphilis is intramuscular penicillin $\mathrm{G}$ benzathine (2.5 million units) (4). On-site access to these injectable medications in clinics facilitates point-of-care treatment and helps mitigate drug resistance to $N$. gonorrhoeae and T. pallidum when these drugs are used instead of the oral antimicrobial drug alternatives. Therefore, we set out to determine a nationally representative estimate of the availability of these medications and examine if differences existed by geographic location and between offices designated and not designated as patient-centered medical homes (PCMHs).

We used the 2016 Physician Induction File of the National Ambulatory Medical Care Survey (5) to assess the number of physicians who treat patients with STIs and had injectable antimicrobial drugs available on-site. The Physician Induction File is a nationally representative survey of office-based, nonfederal physicians in the United States and includes information regarding practice characteristics and habits. Use of the data is restricted, and access is facilitated through the Research Data Center, National Center for Health Statistics, Centers for Disease Control and Prevention, in Hyattsville, Maryland, USA. A total of 1,030 physicians (46.2\% unweighted response rate), representing an estimated 330,581 $(95 \%$ CI 326,994-334,168) physicians in the United States, completed the Physician Induction File in 2016. In this survey, physicians who reported evaluating or treating patients for STIs were asked which antimicrobial drugs they had available on-site for sameday management of gonorrhea and syphilis, including intramuscular ceftriaxone and penicillin $\mathrm{G}$ benzathine at the recommended doses. We determined national estimates of reported on-site, same-day availability for these antimicrobial drugs and stratified results by PCMH designation and US region. We used multiple logistic regression models to determine if $\mathrm{PCMH}$ designation and region were predictive of on-site availability of these 2 medications.

An estimated $45.2 \%(149,483,95 \%$ CI 138,850 $160,116)$ of office-based physicians indicated that they evaluate patients for STIs in their offices. Of these, $77.9 \%$ $(116,479,95 \%$ CI 105,360-127,598) reported not having penicillin $\mathrm{G}$ benzathine available on-site and $56.1 \%$ $(83,827,95 \%$ CI $73,709-93,945)$ reported not having ceftriaxone. Access to both of these drugs was generally higher in the South (Table). Physicians in offices not designated PCMHs were more likely than those in offices designated PCMHs to report lacking on-site availability of ceftriaxone 
Table. On-site availability of drugs to manage gonorrhea and syphilis and likelihood of drug nonavailability by type and location of clinic, United States, 2016*

\begin{tabular}{|c|c|c|c|c|c|}
\hline \multirow[b]{2}{*}{ Category } & \multirow{2}{*}{$\begin{array}{l}\text { Weighted population, } \\
\text { no. }(95 \% \mathrm{Cl})\end{array}$} & \multicolumn{2}{|c|}{ On-site drug availability, \% $(95 \% \mathrm{Cl})$} & \multicolumn{2}{|c|}{$\begin{array}{l}\text { Likelihood of } \\
\text { nonavailability } \dagger\end{array}$} \\
\hline & & Yes & No & $\beta$ & OR $(95 \% \mathrm{Cl})$ \\
\hline \multicolumn{6}{|c|}{$\begin{array}{l}\text { Ceftriaxone, } 250 \mathrm{mg} \text {, intramuscular } \\
\text { PCMH designation } \neq\end{array}$} \\
\hline Yes & $44,028(35,296-52,760)$ & $54.4(42.1-66.3)$ & $45.6(33.7-57.9)$ & \multirow{3}{*}{$\begin{array}{c}\text { Referent } \\
0.71\end{array}$} & \multirow{3}{*}{$\begin{array}{c}\text { Referent } \\
2.03(1.15-3.57)\end{array}$} \\
\hline No & $89,381(79,356-99,406)$ & $37.3(30.0-45.0)$ & $62.7(55.0-7$ & & \\
\hline \multicolumn{4}{|c|}{ Region of office§ } & & \\
\hline Northeast & $33,384(28,666-38,102)$ & $34.3(22.7-47.5)$ & $65.7(52.5-77.3)$ & Referent & \multirow{4}{*}{$\begin{array}{c}\text { Referent } \\
0.53(0.27-1.06) \\
0.76(0.35-1.64) \\
0.54(0.26-1.14)\end{array}$} \\
\hline South & $45,574(39,694-51,454)$ & $49.0(38.4-59.6)$ & $51.0(40.4-61.6)$ & \multirow{3}{*}{$\begin{array}{l}-0.63 \\
-0.28 \\
-0.62\end{array}$} & \\
\hline Midwest & $33,296(28,374-38,218)$ & $41.4(28.9-54.8)$ & $58.6(45.2-71.1)$ & & \\
\hline West & $37,228(31,038-43,418)$ & $48.6(35.8-61.6)$ & $51.4(38.4-6$ & & \\
\hline \multicolumn{6}{|l|}{$\begin{array}{l}\text { Penicillin G benz } \\
\text { PCMH designa }\end{array}$} \\
\hline Yes & $44,028(35,296-52,760$ & $34.2(23.2-46.6)$ & $65.8(53.4-76.8)$ & \multirow{3}{*}{$\begin{array}{c}\text { Referent } \\
1.16\end{array}$} & \multirow{2}{*}{$\begin{array}{c}\text { Referent } \\
3.20(1.63-6.29)\end{array}$} \\
\hline No & $89,381(79,356-99,406)$ & $14.6(9.5-21.1)$ & $(78.9-$ & & \\
\hline \multicolumn{5}{|c|}{ Region of office§ } & \\
\hline Northeast & $33,384(28,666-38,102)$ & $17.8(8.9-30.3)$ & $82.2(69.7-91.1)$ & Referent & \multirow{4}{*}{$\begin{array}{c}\text { Referent } \\
0.43(0.19-1.00) \\
1.25(0.46-3.39) \\
0.88(0.32-2.40)\end{array}$} \\
\hline South & $45,574(39,694-51,454)$ & $32.1(22.8-42.5)$ & $67.9(57.5-77.2)$ & \multirow{3}{*}{$\begin{array}{c}-0.83 \\
0.22 \\
-0.13 \\
\end{array}$} & \\
\hline Midwest & $33,296(28,374-38,218)$ & $15.5(7.3-27.3)$ & $84.5(72.7-92.7)$ & & \\
\hline West & $37,228(31,038-43,418)$ & $19.6(9.4-33.8)$ & $80.4(66.2-90.6)$ & & \\
\hline \multicolumn{6}{|c|}{$\begin{array}{l}\text { *The data source was the National Center for Health Statistics, National Ambulatory Medical Care Survey (5). All analyses were conducted by using } \\
\text { SUDAAN (https://www.rti.org/impact/sudaan-statistical-software-analyzing-correlated-data) to account for the complex sampling design of the survey. OR, } \\
\text { odds ratio; PCMH, patient-centered medical home. } \\
\text { †Likelihood determined by using a logistic regression model that included the factors PCMH designation and region of country. } \beta \text { is the coefficient of the } \\
\text { variable, indicating direction and strength of the association. } \\
\text { łPCMH designation of first-listed National Ambulatory Medical Care Survey-sampled office. An estimated weighted total of } 149,483 \text { office-based } \\
\text { physicians indicated that they evaluate patients for or treat patients with sexually transmitted infections at their first-listed sampled office. PCMH data were } \\
\text { missing (i.e., the physician refused to answer, did not know, or left blank or an instrument error occurred) for } 10.8 \% \text { of weighted office-based physicians } \\
\text { treating gonorrhea and syphilis. } \\
\S \text { Estimates might not sum to the estimated weighted total because of rounding of weighted numbers. }\end{array}$} \\
\hline
\end{tabular}

(odds ratio $2.03,95 \%$ CI 1.15-3.57) and penicillin G benzathine (odds ratio 3.20, 95\% CI 1.63-6.29) (Table).

Our nationally representative analysis demonstrates that most office-based physicians who provide STI services reported not having on-site access to the recommended injectable medications for gonorrhea and syphilis management. The PCMH designation has been noted as an indicator for quality of care by the American Medical Association (6) and thus might be an indication for greater access to more complex treatments and supplies, such as injectable antimicrobial drugs. In addition, previous research has found that PCMHs have larger provider staffs and are affiliated with larger medical groups or health systems that may have access to greater resources, characteristics that might result in these practices having greater access to injectable medications to treat gonorrhea and syphilis patients (7). Differences in drug availability by region were not statistically significant; however, we note that the point estimates of on-site availability were highest among physicians in areas with the highest levels of STIs (the southern United States) and where congenital syphilis has been most commonly observed (the western United States) (1).

We provide a national estimate of the percentage of US physicians treating patients with STIs that report not having the recommended antimicrobial drugs on-site for same-day treatment of gonorrhea and primary and secondary syphilis. In light of our findings, we believe that future research should focus on determining the factors preventing physicians from providing these medications on-site. The costs of obtaining and carrying these medications, as well as issues of storage and shelf life, should be explored to determine if these factors are barriers. In addition, the implications of prescribing alternative treatments or delaying care in situations when medications are not readily available on-site should be further explored. Mitigating the lack of medication availability to treat these infections will help public health officials stop the rise in STI disease.

\section{About the Author}

Dr. Pearson is a health scientist working in the Division of STD Prevention, National Center for HIV/AIDS, Viral Hepatitis, STD, and TB Prevention, at the Centers for Disease Control and Prevention, Atlanta, Georgia, USA. His research interests include the organization, financing, and delivery of health services.

\section{References}

1. Centers for Disease Control and Prevention. Sexually transmitted disease surveillance 2017. Atlanta: US Department of Health and Human Services; 2018.

2. Kirkcaldy RD, Bolan GA, Wasserheit JN. Cephalosporin-resistant gonorrhea in North America. JAMA. 2013;309:185-7. https://doi.org/10.1001/jama.2012.205107

3. Nurse-Findlay S, Taylor MM, Savage M, Mello MB, Saliyou S, Lavayen M, et al. Shortages of benzathine penicillin for prevention 
of mother-to-child transmission of syphilis: an evaluation from multi-country surveys and stakeholder interviews. PLoS Med. 2017;14:e1002473. https://doi.org/10.1371/journal.pmed.1002473

4. Workowski KA, Bolan GA; Centers for Disease Control and Prevention. Sexually transmitted diseases treatment guidelines, 2015. MMWR Recomm Rep. 2015;64(No. RR-3):1-137.

5. Centers for Disease Control and Prevention National Center for Health Statistics. Ambulatory health care data. 2019 Jul 3 [cited 2019 May 29]. https://www.cdc.gov/nchs/ahcd/index.htm

6. American Medical Association. Principles of the patient-centered medical home H-160.919. 2018 [cited 2019 May 29]. https://policysearch.ama-assn.org/policyfinder/detail/Principles $\% 20$ of $\% 20$ the $\% 20$ Patient-Centered $\% 20$ Medical $\% 20 \mathrm{Home} \% 20 \mathrm{H}-$ 160.919? uri=\%2FAMADoc\%2FHOD.xml-0-734.xml

7. McHugh M, Shi Y, Ramsay PP, Harvey JB, Casalino LP, Shortell SM, et al. Patient-centered medical home adoption: results from aligning forces for quality. Health Aff (Millwood). 2016;35:141-9. https://doi.org/10.1377/hlthaff.2015.0495

Address for correspondence: William S. Pearson, Centers for Disease Control and Prevention, 1600 Clifton Rd NE, Mailstop E-80, Atlanta, GA 30329-4027, USA; email: wpearson@cdc.gov

\section{Host Switching of Zoonotic Broad Fish Tapeworm (Dibothriocephalus latus) to Salmonids, Patagonia}

\author{
Roman Kuchta, Alžbeta Radačovská, \\ Eva Bazsalovicsová, Gustavo Viozzi, \\ Liliana Semenas, Marina Arbetman, \\ Tomáš Scholz
}

\begin{abstract}
Author affiliations: Biology Centre of the Czech Academy of Sciences, České Budějovice, Czech Republic (R. Kuchta,

T. Scholz); Institute of Parasitology, Slovak Academy of Sciences, Košice, Slovak Republic (A. Radačovská, E. Bazsalovicsová); Universidad Nacional del Comahue, San Carlos de Bariloche, Argentina (G. Viozzi, L. Semenas, M. Arbetman)
\end{abstract}

DOI: https://doi.org/10.3201/eid2511.190792

Diphyllobothriosis is a reemerging zoonotic disease because of global trade and increased popularity of eating raw fish. We present molecular evidence of host switching of a human-infecting broad fish tapeworm, Dibothriocephalus latus, and use of salmonids as intermediate or paratenic hosts and thus a source of human infection in South America.
$\mathrm{D}$ iphyllobothriosis is an emerging zoonotic disease caused by broad fish tapeworms. Except for the Pacific broad tapeworm (Adenocephalus pacificus), whose life cycle is completed in the sea, all species of the genus Dibothriocephalus (formerly in Diphyllobothrium) were limited to the freshwaters in the Northern Hemisphere (1). However, some of these tapeworms also were reported in the Southern Hemisphere, including South America, especially Patagonia, in the 20th century. Although the introduction routes of these human parasites remain unknown, their larvae (plerocercoids) have appeared in South America in nonnative but economically important salmonids, such as rainbow, brown, and brook trout $(2,3)$.

Several cases of diphyllobothriosis have been reported from South America, and plerocercoids of tapeworms identified as Dibothriocephalus latus and D. dendriticus have been reported in fish (Appendix Table 1, https://wwwnc. cdc.gov/EID/article/25/11/19-0792-App1.pdf). However, species identification was based almost exclusively on morphologic characteristics. Considering general uniformity, intraspecific variability, and shortage of species-specific morphologic traits (especially in plerocercoids), all previous reports of D. latus and $D$. dendriticus tapeworms from South America need verification (4). Reports concerning the most commercially important species of salmonids being infected with $D$. latus tapeworms are especially dubious because this species most likely uses only freshwater percid, esocid, and gadid fish as its second intermediate hosts in the Northern Hemisphere $(1,4)$.

Reliable identification of plerocercoids, which are the source of diphyllobothriosis, is crucial from the epidemiologic point of view because salmonids are of great economic value in South America as a food source for local populations, sport fishing, and exportation (5). We provide molecular evidence of second intermediate or paratenic host switching of human-infecting D. latus tapeworms in Patagonia, South America.

We found a total of 44 plerocercoids in 3 salmonid species: from Lake Gutiérrez, Rio Negro, Argentina (October 2017), rainbow trout (Oncorhynchus mykiss), of which $2 / 7$ fish examined were infected; brown trout (Salmo trutta), of which 3/4 were infected; and brook trout (Salvelinus fontinalis), of which 5/10 were infected; and from Lake Alicura, Neuquén, Argentina (April 2018), brown trout, of which $3 / 4$ were infected. Most plerocercoids were encysted in the body cavity, mainly among the pyloric ceca, and only a few were free in the muscle. We selected, photographed, and sequenced the partial cox 1 gene of 22 larvae in accordance with the procedure described by Wicht et al. (6). We also photodocumented morphologic vouchers (hologenophores) of sequenced specimens (Figure).

Our morphologic and molecular evaluation revealed the presence of $D$. dendriticus plerocercoids in 12 fish (8 